\title{
Assigning Clinical Significance and Symptom Severity Using the Zung Scales: Levels of Misclassification Arising from Confusion between Index and Raw Scores
}

\author{
Debra A. Dunstan $(\mathbb{D})$ and Ned Scott \\ School of Behavioural, Cognitive and Social Sciences, University of New England, Armidale, NSW 2351, Australia \\ Correspondence should be addressed to Debra A. Dunstan; ddunstan@une.edu.au
}

Received 20 June 2017; Accepted 19 December 2017; Published 21 January 2018

Academic Editor: Bernard Sabbe

Copyright (c) 2018 Debra A. Dunstan and Ned Scott. This is an open access article distributed under the Creative Commons Attribution License, which permits unrestricted use, distribution, and reproduction in any medium, provided the original work is properly cited.

\begin{abstract}
Background. The Zung Self-Rating Depression Scale (SDS) and Self-Rating Anxiety Scale (SAS) are two norm-referenced scales commonly used to identify the presence of depression and anxiety in clinical research. Unfortunately, several researchers have mistakenly applied index score criteria to raw scores when assigning clinical significance and symptom severity ratings. This study examined the extent of this problem. Method. 102 papers published over the six-year period from 2010 to 2015 were used to establish two convenience samples of 60 usages of each Zung scale. Results. In those papers where cut-off scores were used (i.e., 45/60 for SDS and $40 / 60$ for SAS), up to $51 \%$ of SDS and $45 \%$ of SAS papers involved the incorrect application of index score criteria to raw scores. Inconsistencies were also noted in the severity ranges and cut-off scores used. Conclusions. A large percentage of publications involving the Zung SDS and SAS scales are using incorrect criteria for the classification of clinically significant symptoms of depression and anxiety. The most common error-applying index score criteria to raw scores-produces a substantial elevation of the cut-off points for significance. Given the continuing usage of these scales, it is important that these inconsistencies be highlighted and resolved.
\end{abstract}

\section{Introduction}

Of the conditions contributing to the global disability burden of mental illness, anxiety and depression are the most prevalent disorders $[1,2]$. However, while these are conceptually distinct constructs $[3,4]$, they present as highly comorbid conditions $[5,6]$. Further, while an absence of positive affect is considered unique to depression, and other specific factors are unique to particular anxiety disorders (e.g., physiological arousal to posttraumatic stress disorder and panic disorder), the presence of a high level of general distress and negative affect is common to both types of disorder $[7,8]$. For these reasons, researchers and clinicians often concurrently screen for the presence and severity of both disorders using selfreport psychometric tools developed for this purpose.

Self-report measures of mental disorders may be criterion-referenced or norm-referenced. Criterion-referenced measures are used to make a diagnosis based on the endorsement of criteria listed in published diagnostic classification systems. Individuals are diagnosed with or without a disorder based upon the presence or absence of these criteria $[9,10]$. In contrast to criterion-referenced measures, norm-referenced measures compare individuals' test results to those of an appropriate peer or normative group. These scales typically suggest score ranges linked to symptom severity descriptors and have a "clinically significant" total scale score cut-off point beyond which scores are considered indicative of the presence of a disorder (see Table 1).

The Zung Self-Rating Depression Scale (SDS) [11] is a commonly utilized norm-referenced scale. The SDS is a 20item Likert scale covering symptoms that were identified in factor analytic studies of the syndrome of depression [11]. Items tap psychological and physiological symptoms and are rated by respondents according to how each applied to them within the past week, using a 4-point scale ranging from 1 (none, or a little of the time) to 4 (most, or all of the time). The scale has a raw score range of 20 to 80 points. The raw score is then converted to an index score by dividing the raw score 
TABLE 1: Clinical cut-off and severity ranges.

\begin{tabular}{lcccc}
\hline & \multicolumn{2}{c}{ SDS $^{1}$} & \multicolumn{2}{c}{ SAS $^{2}$} \\
& Raw & Index & Raw & Index \\
\hline Clinical cut-off & 40 & 50 & 36 & 45 \\
Severity range & & & & \\
$\quad$ Mild-moderate & $40-47$ & $50-59$ & & \\
$\quad$ Moderate-severe & $48-55$ & $60-69$ & & \\
$\quad$ Severe & $56+$ & $70+$ & & \\
\hline Note. $^{1}$ Zung (1974, pp. $\left.176-177\right) ;{ }^{2}$ Zung (1980, p. 18). &
\end{tabular}

by the maximum score (80) and either expressing this as a decimal or multiplying by 100 to express it as a whole number with an index score range of 25 to 100 . Index scores of 25 to 49 indicate nil depression, 50-59 indicate mild to moderate depression, 60-69 indicate moderate to severe depression, and scores over 70 indicate severe depression [12].

Zung [13] also devised a similar 20-item scale to screen for the presence of clinical anxiety: the Self-Rating Anxiety Scale (SAS). Items tap affective and somatic symptoms selected from the diagnostic criteria listed in the Diagnostic and Statistical Manual of Mental Orders (DSM II) current at the time [14]. The scoring structure and index score conversion is similar to that for the SDS. However, for the SAS, the situation regarding cut-off scores is less clear: Zung [6] noted in an early study that all "normal subjects" returned an SAS index score below 50, but later he set an index score of 45 (raw score $=36)$ as a cut-off point for clinically significant anxiety [15]. Moreover, score ranges for degrees of severity have not been published in the scientific literature.

Unfortunately, the literature reveals a number of discrepancies in the way the Zung scales have been used, reported, and interpreted. In particular, several researchers have mistakenly applied index score cut-offs to raw scores in assigning clinical significance and symptom severity ratings (e.g., $[76,118,119])$. In their Methods sections, these researchers describe the calculation of a total raw score and a "cut-off" score of 50 for morbidity. However, " 50 " is the index cut-off score set by Zung for the SDS, and this equates a raw score of 40 . Using a raw score cut-off of 50 considerably reduces the proportion of cases classed as clinically significant. Another issue is that some researchers have applied severity range descriptors to the SAS when, as stated above, no such descriptors exist in the literature (e.g., [119]).

It is likely that errors in the scoring and interpretation of the Zung scales emanate from two sources that involve a failure to refer to the original publications. One is a reliance on the (erroneous) scale descriptions of other authors. The other is that some clinicians and researchers may have accessed scale information from sourcebooks of psychometric measures where distinctions between index and raw scores are imprecise. For example, both Fischer and Corcoran [120] and Schutte and Malouff [121] fail to clearly specify that recommended cut-off points are based on index and not raw scores.
TABLE 2: Number of papers applying cut-offs correctly and incorrectly.

\begin{tabular}{lcc}
\hline & SDS $(n=60)$ & SAS $(n=60)$ \\
\hline Cut-offs not used & 15 & 20 \\
Consistent use: raw scores & 9 & 8 \\
Consistent use: index scores & 13 & 14 \\
Incorrect use & 16 & 8 \\
Unclear application & 7 & 10 \\
\hline
\end{tabular}

This paper examines the extent to which these scales have been incorrectly interpreted in the literature. Given the scales' continued application, it is important that these inconsistencies in interpretation are highlighted and corrected.

\section{Method}

To investigate the extent to which the Zung scales are being wrongly applied, a search of the ProQuest full text database was conducted. Searches were done for each of the six calendar years from 2010 to 2015, using the terms "Zung Depression Scale," "Zung Self-Rating Depression Scale," "Zung Anxiety Acale," "Zung Self-Rating Anxiety Scale," and "Zung Self-Rating Scale." Searches were limited to scholarly articles. For each calendar year, the results were examined in the order presented by the database search engine and, for both the SDS and the SAS, the first ten articles that used that scale to collect new data were selected to form a "convenience" sample indicative of recent use of these scales. Articles reporting on studies using both the SDS and the SAS were included, but theoretical articles and metaanalyses were not. In total, 102 articles were sourced and explored for misinterpretation of both scales. The disciplines covered in the articles were psychiatry (25\%), psychology (9\%), cardiology (6\%), oncology (5\%), neurology (5\%), and gynecology (5\%). The remaining $45 \%$ were other medical disciplines.

The results for each paper were recorded against a checklist. Examination initially focused on whether cut-off scores and severity ranges were applied. When this was done, the usage was coded according to the following categories:

(1) Consistent use of raw scores: paper uses raw scores only with cut-off scores and/or severity ranges appropriately modified.

(2) Consistent use of index scores: paper details conversion to index scores and uses index score cut-offs/severity ranges.

(3) Incorrect application: index cut-off scores/severity ranges are specifically applied to raw scores.

(4) Unclear application: paper uses index cut-off/severity ranges without mention of conversion from raw scores: however, there was no conclusive evidence that this was not done.

(5) Not utilized: cut-off scores/severity ranges are not stated or used. 


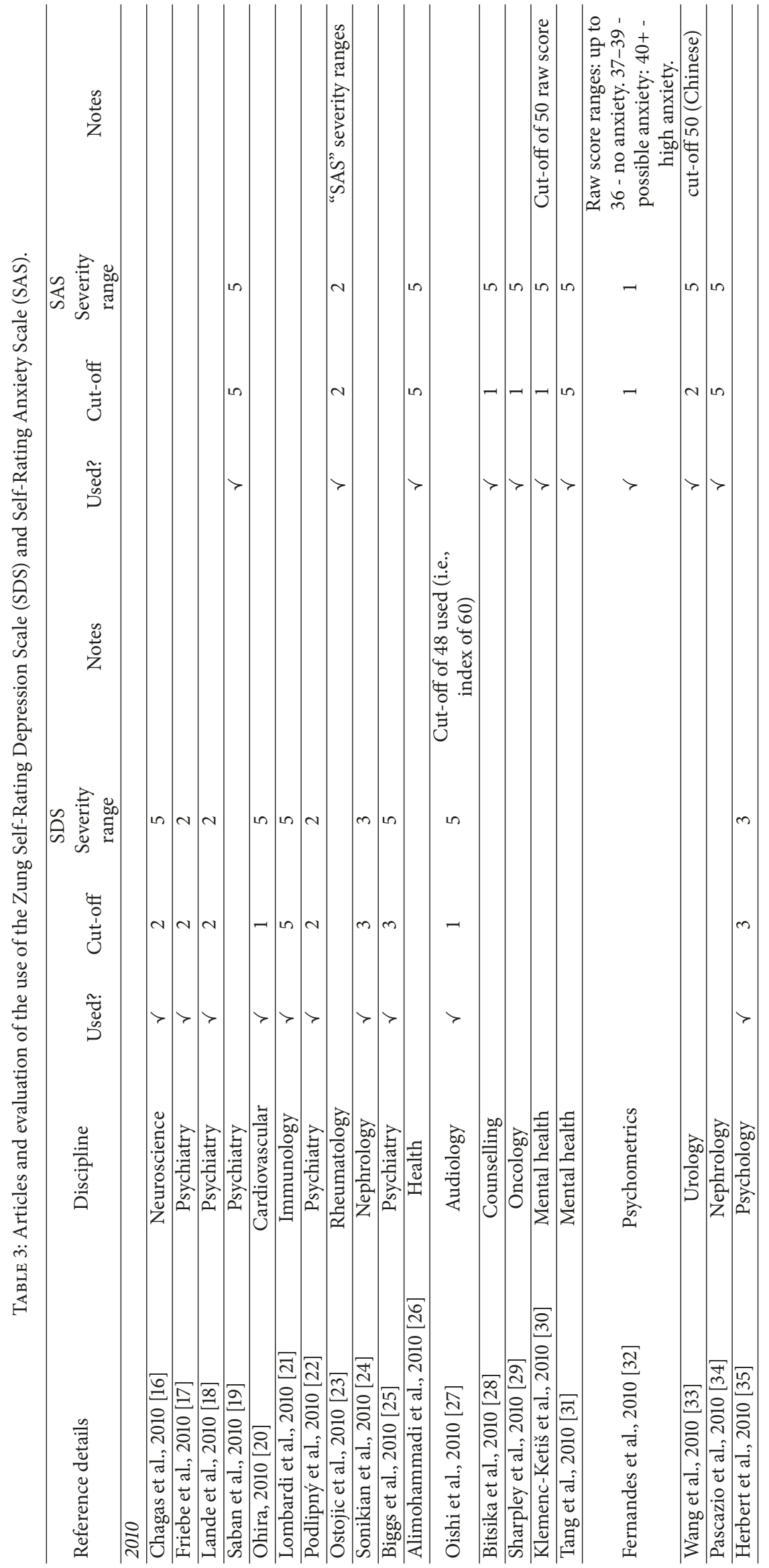




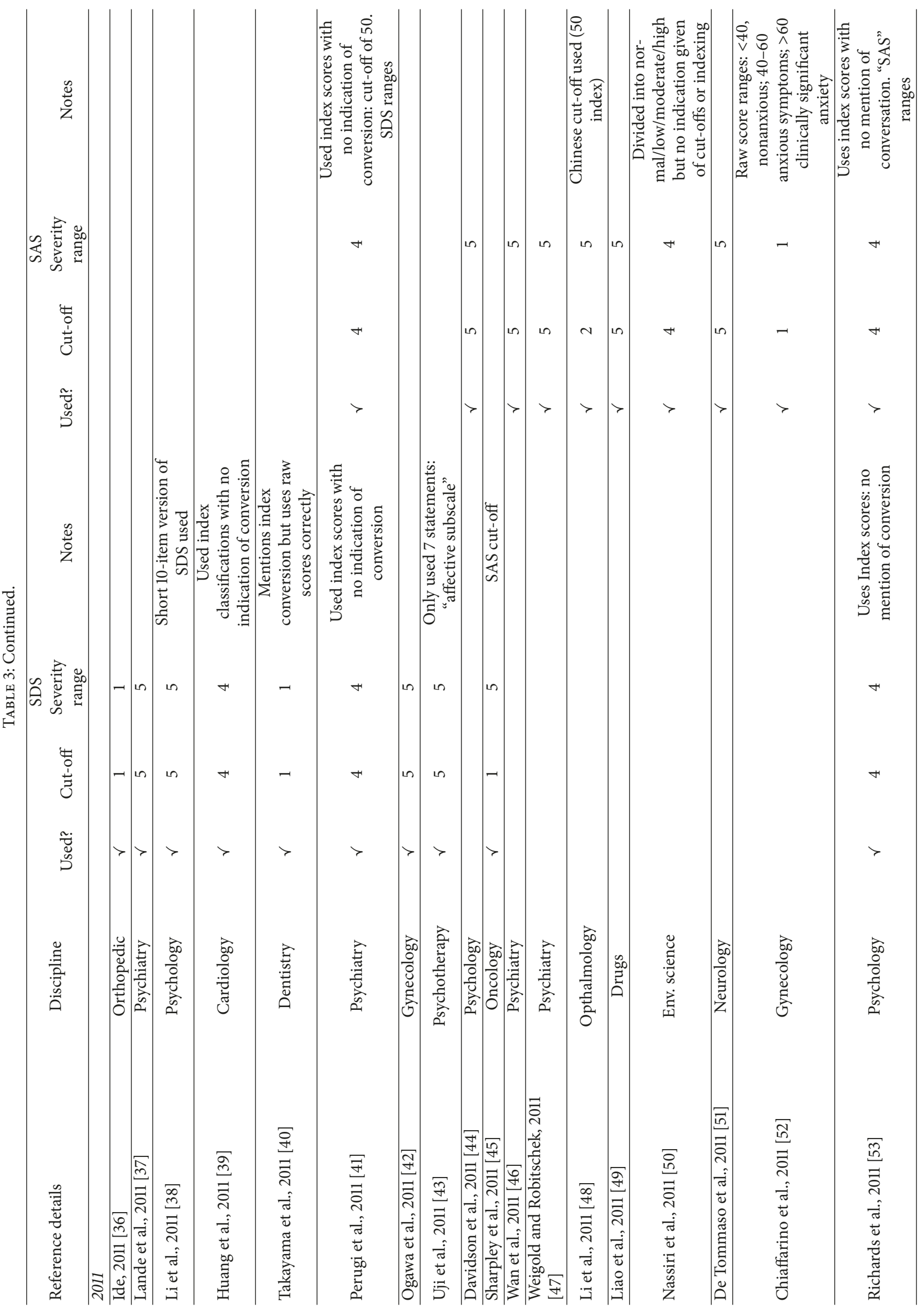




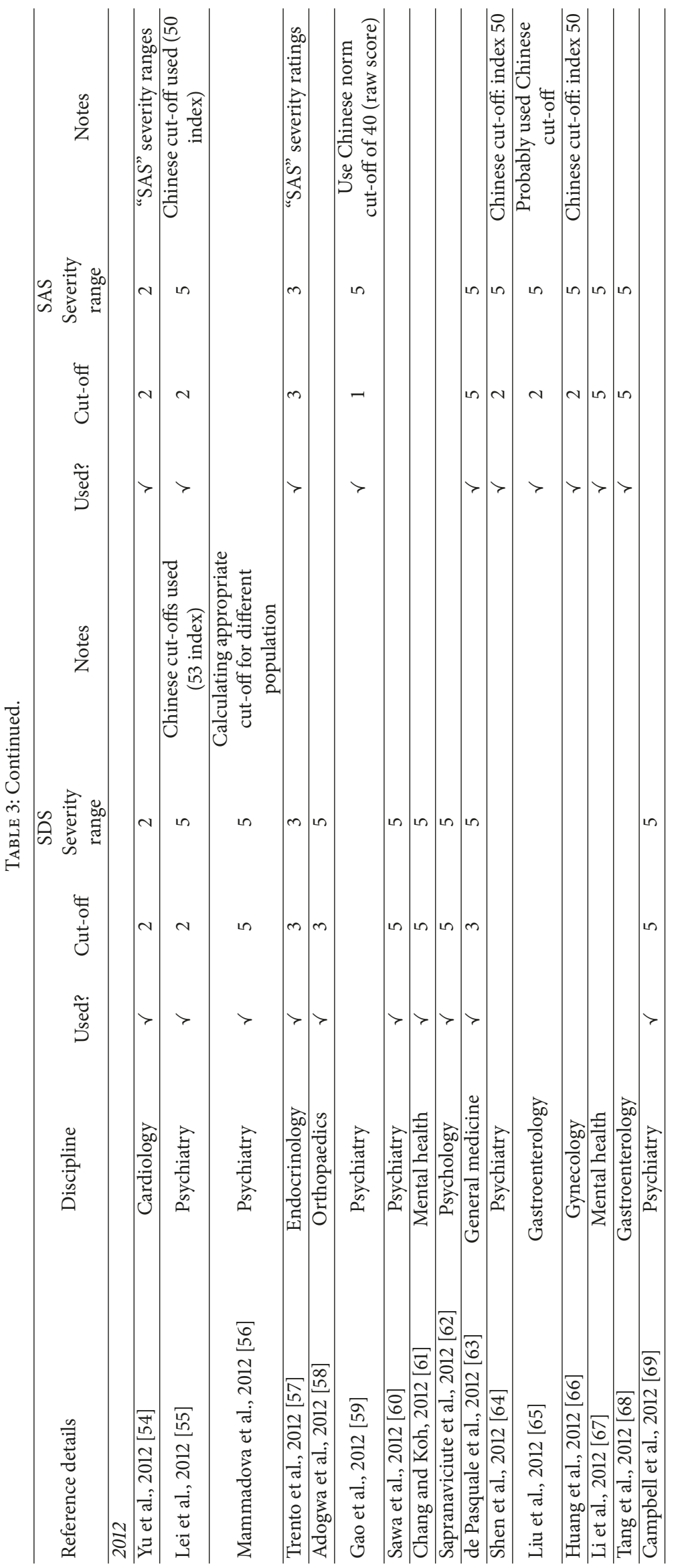




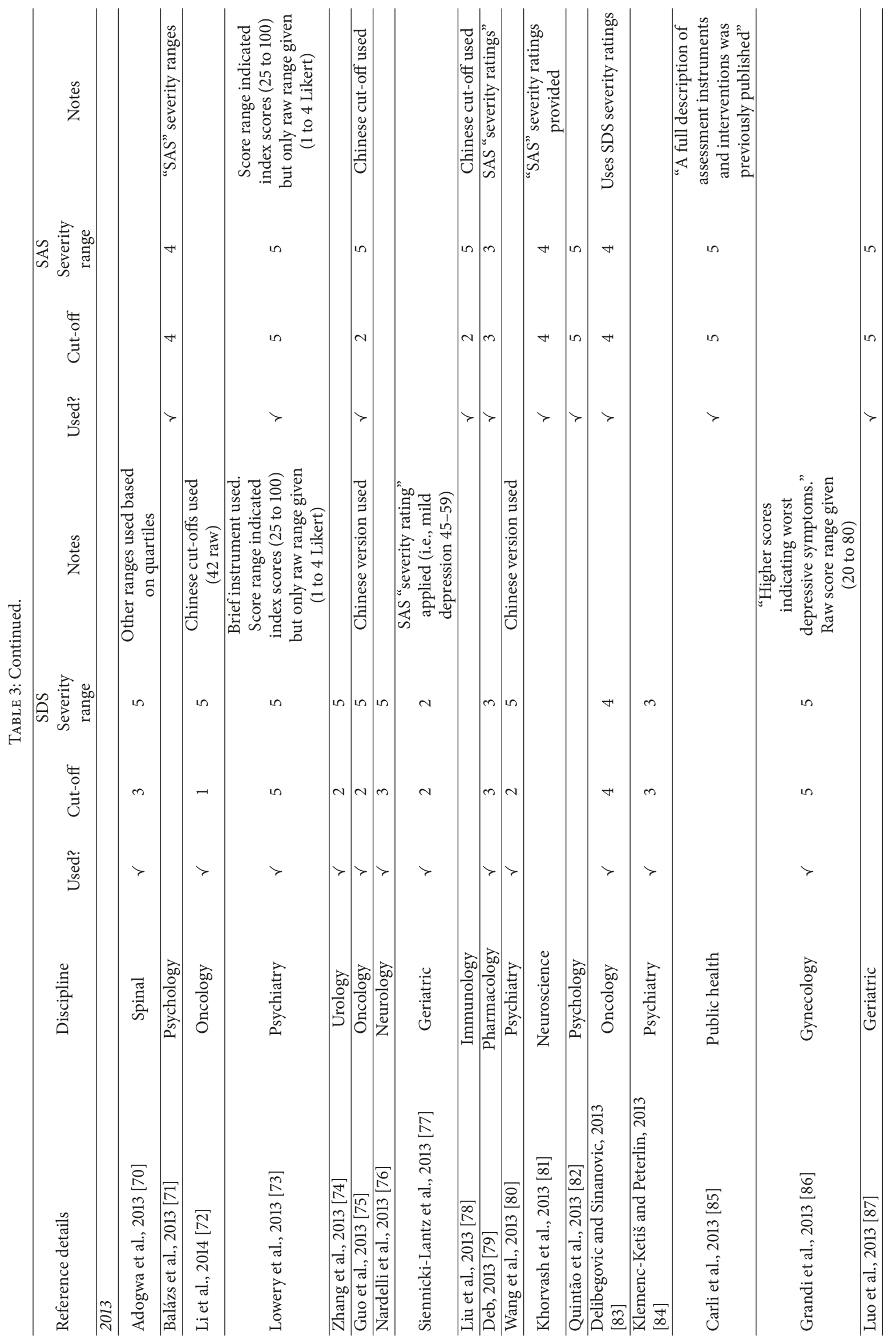




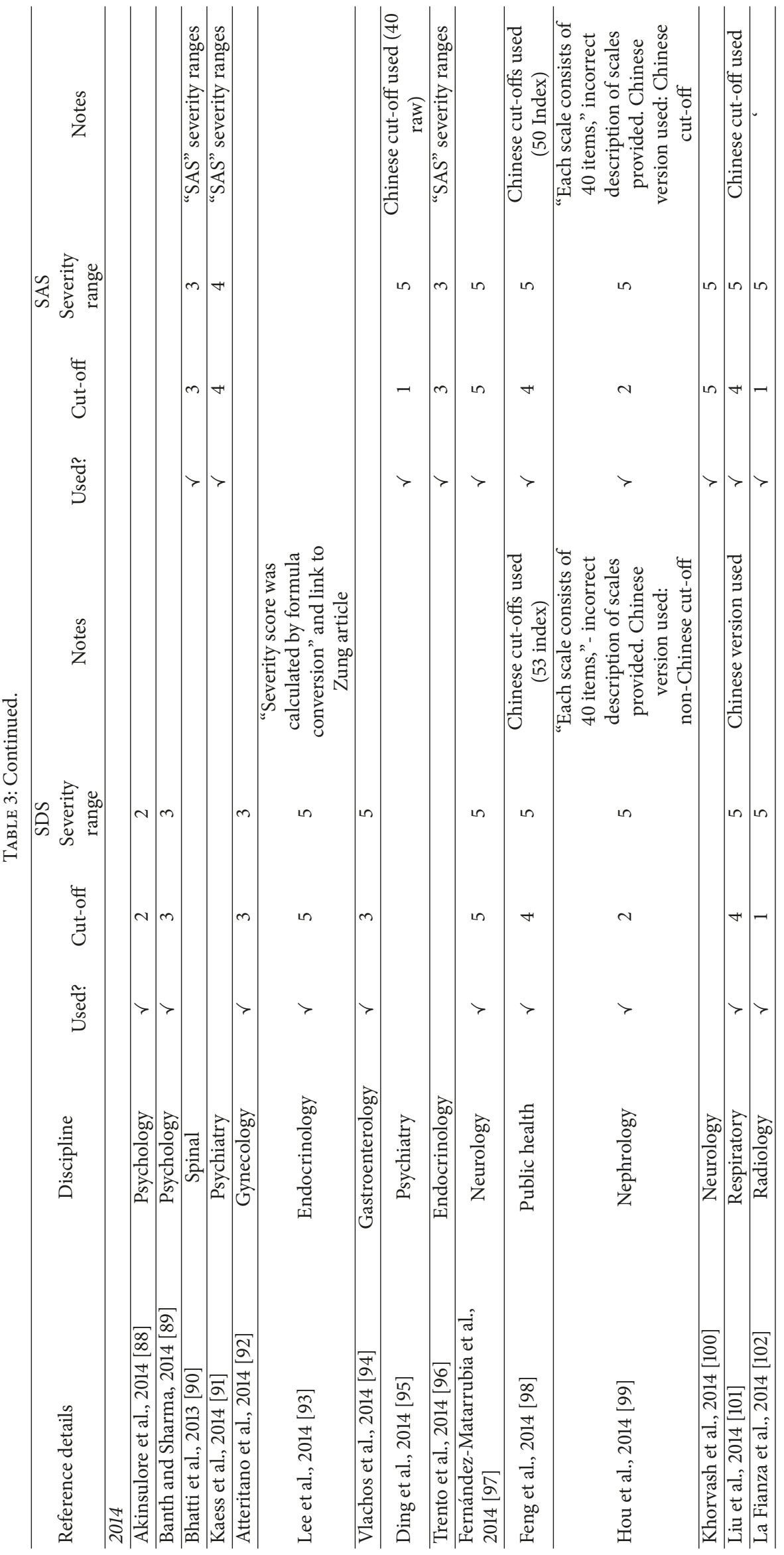




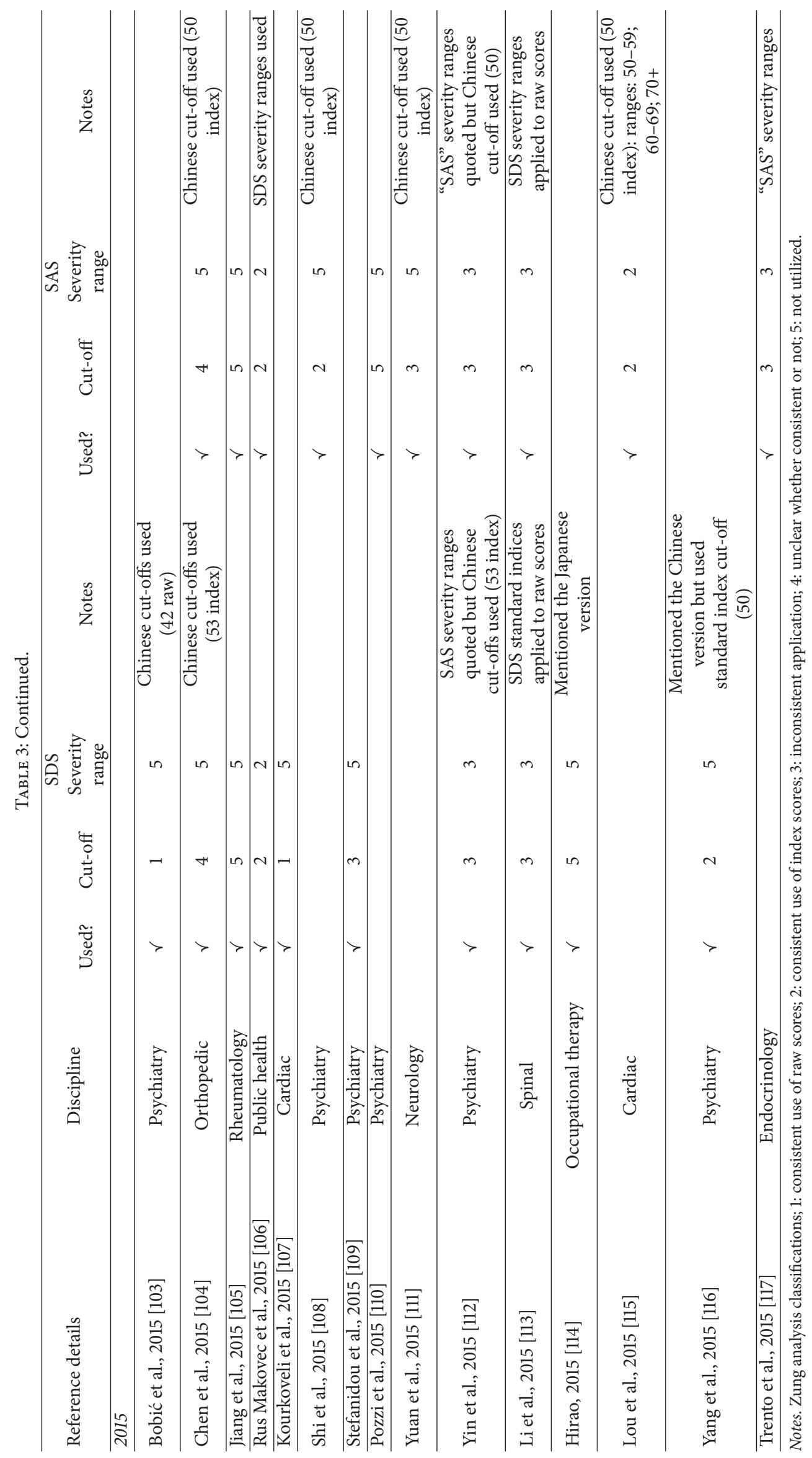


TABLE 4: Number of papers applying severity ranges correctly and incorrectly.

\begin{tabular}{lcc}
\hline & SDS $(n=60)$ & SAS $(n=60)$ \\
\hline Severity ranges not used & 37 & 40 \\
Consistent use: raw scores & 2 & 2 \\
Consistent use: index scores & 7 & 4 \\
Incorrect use & 9 & 7 \\
Unclear application & 5 & 7 \\
\hline
\end{tabular}

Notes were also taken where the cut-off and severity ranges applied were different from Zung's [12, 15] recommendations.

\section{Results}

Cut-offs for the presence of a disorder were applied in 45 of the 60 papers where the SDS was used and in 40 of the 60 where the SAS was used. For the SDS, index cut-offs were incorrectly applied to raw scores in $16(35 \%)$ of these 45 papers, with a further $7(16 \%)$ papers in which application was unclear. For the SAS, 8 (20\%) of the 40 papers revealed incorrect application, with a further $10(25 \%)$ being unclear (Table 2).

As shown in Table 3, the level at which cut-offs were set did not always accord with Zung's recommendations. In particular, alternative norms have been developed for use in Chinese populations with the cut-off for the SDS set at an index score of 53 (raw score, 42) and, for the SAS, at 50 (raw score, 40). Further, one of the SDS papers used the SAS cutoff (index 45, raw 36) and three of the SAS papers used the SDS cut-off (index 50, raw 40). Another three papers used the newly developed SDS cut-offs for a Chinese population but applied these to European samples. Finally, one of the SDS papers set a much higher cut-off index score of 60 (raw 48).

Severity ranges were utilized considerably less often. Specifically 23 of the 60 SDS papers included them but in $9(39 \%)$ of these cases, index score ranges were incorrectly applied to raw scores, with a further $5(22 \%)$ cases falling into the unclear category. Figures for the SAS followed a similar pattern despite the absence of any official ranges in the scientific literature. Twenty of the 60 SAS papers include such scales, with index score ranges being incorrectly applied to raw scores in 7 (35\%) of these cases, with a further 7 (35\%) falling into the unclear category (Table 4).

The most common severity range applied to the SAS is based on the recommended cut-off of 45 (index). In index score terms, severity ranges are $45-59$ mild to moderate anxiety, 60-74 moderate to severe anxiety, and $75+$ severe anxiety. Thirteen of the 20 SAS papers utilizing severity ranges employed the above. A further four used the SDS severity ranges, while two utilized different ranges altogether and the final paper merely specified descriptors without detailing the numerical criteria. The recommended SDS severity ranges were applied in all SDS papers but two, which instead used the "unofficial" SAS ranges detailed above.

\section{Discussion}

This study examined a sample of recent scientific publications for the application of raw scores, index scores, and symptom severity ranges when interpreting total scores on the Zung SDS and SAS. Although the findings were based on a "convenience" rather than a random sample of papers, they provide clear evidence of a significant problem in the application of Zung scales across the literature. On the basis of the papers examined here, confusion between raw and index scores means that when cut-offs are applied to indicate the presence/absence of disorder, they are applied incorrectly in $35-51 \%$ of cases for the SDS and $20-45 \%$ of cases for the SAS (depending on the proportion of unclear cases that involve incorrect application).

This incorrect application of index score cut-offs to raw scores substantially elevates the score required to be classified in the clinical range: in index terms, from 50 to 63 on the SDS and from 45 to 56 on the SAS. The potential impact on study findings does not need elaboration.

Quite apart from the issue of cut-off scores being incorrectly applied, the inconsistency introduced by the use of two distinct sets of scores to represent the same scale makes crossstudy comparisons unnecessarily difficult. (Across the studies in our sample, raw scores were used approximately $40 \%$ of the time and index scores on $60 \%$ of occasions.) Given that the transformation to index scores achieves no purpose other than to decimalize the maximum score, the simplest solution might be to abolish the use of index scores altogether.

Additionally, some confusion exists between the two Zung scales with SDS cut-offs applied to the SAS and vice versa. The same applies to severity ranges for the two scales, if one accepts that an unofficial scale for the SAS has evolved in the literature. The scientific basis of this scale remains highly questionable.

The Zung scales continue to be widely used and potentially remain a valuable means of screening for the presence of anxiety and depression. However, if scale scores are to be reliably interpreted, it is a matter of some urgency that current confusion regarding scale cut-off and severity ranges is resolved and the application of these scales is standardized in future studies.

\section{Conflicts of Interest}

The authors declare that they have no conflicts of interest.

\section{Acknowledgments}

The authors thank Natalya O'Keefe for her work as a research assistant during the data collection phase of the study.

\section{References}

[1] G. Andrews, S. Henderson, and W. Hall, "Prevalence, comorbidity, disability and service utilisation: Overview of the Australian National Mental Health Survey," The British Journal of Psychiatry, vol. 178, pp. 145-153, 2001.

[2] R. C. Kessler, "The global burden of mental disorders: an update from the WHO World Mental Health (WMH) surveys," 
Epidemiologia E Psichiatria Sociale, vol. 18, no. 1, pp. 23-33, 2009.

[3] T. A. Brown, B. F. Chorpita, W. Korotitsch, and D. H. Barlow, "Psychometric properties of the Depression Anxiety Stress Scales (DASS) in clinical samples," Behaviour Research and Therapy, vol. 35, no. 1, pp. 79-89, 1997.

[4] L. A. Feldman, "Distinguishing depression and anxiety in selfreport: Evidence from confirmatory factor analysis on nonclinical and clinical samples," Journal of Consulting and Clinical Psychology, vol. 61, no. 4, pp. 631-638, 1993.

[5] D. Dozois, K. Dobson, and H. Westra, "The comorbidity of anxiety and depression, and the implications of comorbidity for prevention," in in The Prevention of Anxiety And Depression: Theory, Research And Practice, D. Dozois and K. Dobson, Eds., pp. 261-280, American Psychological Association, Washington, DC, USA, 2004.

[6] W. W. K. Zung, "The measurement of affects: Depression and anxiety," Modern Problems of Pharmacopsychiatry, vol. 7, pp. 170-188, 1974.

[7] L. A. Clarke and D. Watson, "Theoretical and empirical issues in differentiating depression from anxietyaspects of mood," in in Psychosocial Aspects of Mood Disorders, J. Becker and A. Kleinman, Eds., pp. 39-65, Lawrence Erlbaum Associates, Hillsdale, NJ, USA, 1991.

[8] D. Watson, "Differentiating the mood and anxiety disorders: A quadripartite model," Annual Review of Clinical Psychology, vol. 5, pp. 221-247, 2009.

[9] D. J. Kupfer, "Dimensional models for research and diagnosis: A current dilemma," Journal of Abnormal Psychology, vol. 114, no. 4, pp. 557-559, 2005.

[10] T. J. Trull, Clinical Psychology, Cengage Learning, Belmont, CA, USA, 7th edition, 2005.

[11] W. W. Zung, "A self-rating depression scale," Archives of General Psychiatry, vol. 12, pp. 63-70, 1965.

[12] W. W. K. Zung, "From Art to Science: The Diagnosis and Treatment of Depression," Archives of General Psychiatry, vol. 29, no. 3, pp. 328-337, 1973.

[13] W. W. Zung, "A rating instrument for anxiety disorders," Psychosomatic Medicine, vol. 12, no. 6, pp. 371-379, 1971.

[14] American Psychiatric Association, Diagnostic and Statistical Manual of Mental Disorders, Author, Washington, DC, USA, 2nd edition, 1968.

[15] W. W. K. Zung, How normal is anxiety? Current Concepts, Upjohn, Durham, North Carolina, USA, 1980.

[16] M. H. N. Chagas, V. Tumas, S. R. Loureiro et al., "Validity of a Brazilian version of the Zung self-rating depression scale for screening of depression in patients with Parkinson's disease," Parkinsonism \& Related Disorders, vol. 16, no. 1, pp. 42-45, 2010.

[17] A. Friebe, M. Horn, F. Schmidt et al., "Dose-dependent development of depressive symptoms during adjuvant interferon- $\alpha$ treatment of patients with malignant melanoma," Psychosomatics, vol. 51, no. 6, pp. 466-473, 2010.

[18] R. G. Lande, L. B. Williams, J. L. Francis, C. Gragnani, and M. L. Morin, "Efficacy of biofeedback for post-traumatic stress disorder," Complementary Therapies in Medicine, vol. 18, no. 6 , pp. 256-259, 2010.

[19] A. Saban, A. J. Flisher, and G. Distiller, "Association between psychopathology and substance use among school-going adolescents in Cape Town, South Africa," Journal of Psychoactive Drugs, vol. 42, no. 4, pp. 467-476, 2010.
[20] T. Ohira, "Psychological distress and cardiovascular disease: The Circulatory Risk in Communities Study (CIRCS)," Journal of Epidemiology, vol. 20, no. 3, pp. 185-191, 2010.

[21] D. Lombardi, L. T. Mizuno, and A. Thornberry, "The use of the Zung Self-Rating Depression Scale to assist in the case management of patients living with HIV/AIDS," Care Management Journals, vol. 11, no. 4, pp. 210-216, 2010.

[22] J. Podlipný et al., "Lower serum levels of interleukin-6 in a population sample with symptoms of depression than in a population sample without symptoms of depression," Physiological Research, vol. 59, no. 1, p. 121, 2010.

[23] P. Ostojic, S. Zivojinovic, T. Reza, and N. Damjanov, "Symptoms of depression and anxiety in Serbian patients with systemic sclerosis: impact of disease severity and socioeconomic factors," Modern Rheumatology, vol. 20, no. 4, pp. 353-357, 2010.

[24] M. Sonikian, P. Metaxaki, D. Papavasileiou et al., "Effects of interleukin-6 on depression risk in dialysis patients," American Journal of Nephrology, vol. 31, no. 4, pp. 303-308, 2010.

[25] Q. M. Biggs, C. S. Fullerton, J. J. Reeves, T. A. Grieger, D. Reissman, and R. J. Ursano, "Acute stress disorder, depression, and tobacco use in disaster workers following 9/11.," American Journal of Orthopsychiatry, vol. 80, no. 4, pp. 586-592, 2010.

[26] I. Alimohammadi et al., "Factors affecting road traffic noise annoyance among white-collar employees working in Tehran," Journal of Environmental Health Science and Engineering, vol. 7, no. 1, p. 25, 2010.

[27] N. Oishi, S. Kanzaki, S. Shinden, H. Saito, Y. Inoue, and K. Ogawa, "Effects of selective serotonin reuptake inhibitor on treating tinnitus in patients stratified for presence of depression or anxiety," Audiology and Neurotology, vol. 15, no. 3, pp. 187193, 2010

[28] V. Bitsika, C. F. Sharpley, and T. C. Melhem, "Gender differences in factor scores of anxiety and depression among Australian university students: Implications for counselling interventions," Canadian Journal of Counselling and Psychotherapy (Online), vol. 44, no. 1, p. 51, 2010.

[29] C. F. Sharpley, V. Bitsika, and D. R. H. Christie, "Incidence and nature of anxiety-depression comorbidity in prostate cancer patients," Journal of Men's Health, vol. 7, no. 2, pp. 125-134, 2010.

[30] Z. Klemenc-Ketiš, J. Kersnik, and D. Novak-Glavač, "Determinants of depression and anxiety in family practice patients with comorbidities," Wiener Klinische Wochenschrift, vol. 122, no. 2, pp. 35-39, 2010.

[31] J. Tang, Y. Yu, Y. Du, Y. Ma, H. Zhu, and Z. Liu, "Association between actual weight status, perceived weight and depressive, anxious symptoms in Chinese adolescents: A cross-sectional study," BMC Public Health, vol. 10, article no. 594, 2010.

[32] L. Fernandes, J. Fonseca, S. Martins et al., "Association of anxiety with asthma: Subjective and objective outcome measures," Psychosomatics, vol. 51, no. 1, pp. 39-46, 2010.

[33] W.-W. Wang, C.-H. Deng, L.-W. Chen, L.-Y. Zhao, J.-C. Mo, and X.-A. Tu, "Psychosexual adjustment and age factors in 130 men undergone hypospadias surgery in a Chinese hospital," Andrologia, vol. 42, no. 6, pp. 384-388, 2010.

[34] L. Pascazio, I. B. Nardone, A. Clarici et al., "Anxiety, depression and emotional profile in renal transplant recipients and healthy subjects: A comparative study," Transplantation Proceedings, vol. 42, no. 9, pp. 3586-3590, 2010.

[35] G. L. Herbert, V. McCormack, and J. L. Callahan, "An investigation of the object relations theory of depression," Psychoanalytic Psychology, vol. 27, no. 2, pp. 219-234, 2010. 
[36] M. Ide, "The association between depressive mood and pain amongst individuals with limb amputations," European Journal of Trauma and Emergency Surgery, vol. 37, no. 2, pp. 191-195, 2011.

[37] R. G. Lande, L. B. Williams, C. Gragnani, and Albert Tsai, "Effectiveness of light therapy for depression among active duty service members: A nonrandomized controlled pilot trial," Complementary Therapies in Medicine, vol. 19, no. 3, pp. 161-163, 2011.

[38] L. Li, L.-J. Liang, Y. Y. Ding, and G. Ji, "Facing HIV as a Family: Predicting Depressive Symptoms With Correlated Responses," Journal of Family Psychology, vol. 25, no. 2, pp. 202-209, 2011.

[39] K. Huang, X. Deng, D. He et al., "Prognostic implication of earthquake-related loss and depressive symptoms in patients with heart failure following the 2008 earthquake in Sichuan," Clinical Cardiology, vol. 34, no. 12, pp. 755-760, 2011.

[40] Y. Takayama, E. Miura, K. Miura, S. Ono, and C. Ohkubo, "Condition of depressive symptoms among Japanese dental students," Odontology, vol. 99, no. 2, pp. 179-187, 2011.

[41] G. Perugi, P. L. Canonico, P. Carbonato et al., "Unexplained somatic symptoms during major depression: Prevalence and clinical impact in a national sample of italian psychiatric outpatients," Psychopathology, vol. 44, no. 2, pp. 116-124, 2011.

[42] M. Ogawa, K. Takamatsu, and F. Horiguchi, "Evaluation of factors associated with the anxiety and depression of female infertility patients," BioPsychoSocial Medicine, vol. 5, article no. $15,2011$.

[43] M. Uji, T. Kitamura, and T. Nagata, "Self-conscious affects: Their adaptive functions and relationship to depressive mood," American Journal of Psychotherapy, vol. 65, no. 1, pp. 27-46, 2011.

[44] C. L. Davidson, L. R. Wingate, D. M. Grant, M. R. Judah, and A. C. Mills, "Interpersonal suicide risk and ideation: The influence of depression and social anxiety," Journal of Social and Clinical Psychology, vol. 30, no. 8, pp. 842-855, 2011.

[45] C. F. Sharpley, V. Bitsika, and D. R. H. Christie, "Understanding the functionality of depression among Australian breast cancer patients: Implications for cognitive and behavioural interventions," International Journal of Behavioral Medicine, vol. 18, no. 4, pp. 319-324, 2011.

[46] Y.-H. Wan, C.-L. Hu, J.-H. Hao, Y. Sun, and F.-B. Tao, "Deliberate self-harm behaviors in Chinese adolescents and young adults," European Child and Adolescent Psychiatry, vol. 20, no. 10, pp. 517-525, 2011.

[47] I. K. Weigold and C. Robitschek, "Agentic personality characteristics and coping: Their relation to trait anxiety in college students," American Journal of Orthopsychiatry, vol. 81, no. 2, pp. 255-264, 2011.

[48] M. Li, L. Gong, X. Sun, and W. J. Chapin, "Anxiety and depression in patients with dry eye syndrome," Current Eye Research, vol. 36, no. 1, pp. 1-7, 2011.

[49] Y. Liao, J. Tang, T. Liu, X. Chen, T. Luo, and W. Hao, "Sleeping problems among Chinese heroin-dependent individuals," The American Journal of Drug and Alcohol Abuse, vol. 37, no. 3, pp. 179-183, 2011.

[50] P. Nassiri et al., "Assessment of noise induced psychological stresses on printery workers," International Journal of Environmental Science and Technology, vol. 8, no. 1, pp. 169-176, 2011.

[51] M. De Tommaso, A. Federici, C. Serpino et al., "Clinical features of headache patients with fibromyalgia comorbidity," The Journal of Headache and Pain, vol. 12, no. 6, pp. 629-638, 2011.
[52] F. Chiaffarino, M. P. Baldini, C. Scarduelli et al., "Prevalence and incidence of depressive and anxious symptoms in couples undergoing assisted reproductive treatment in an Italian infertility department," European Journal of Obstetrics \& Gynecology and Reproductive Biology, vol. 158, no. 2, pp. 235-241, 2011.

[53] A. Richards, J. Ospina-Duque, M. Barrera-Valencia et al., "Posttraumatic stress disorder, anxiety and depression symptoms, and psychosocial treatment needs in colombians internally displaced by armed conflict: A mixed-method evaluation," Psychological Trauma: Theory, Research, Practice, and Policy, vol. 3, no. 4, pp. 384-393, 2011.

[54] S. Yu, Q. Zhao, P. Wu et al., "Effect of anxiety and depression on the recurrence of paroxysmal atrial fibrillation after circumferential pulmonary vein ablation," Journal of Cardiovascular Electrophysiology, vol. 23, no. 1, pp. S17-S23, 2012.

[55] M. Lei, C. Li, X. Xiao, J. Qiu, Y. Dai, and Q. Zhang, "Evaluation of the psychometric properties of the Chinese version of the Resilience Scale in Wenchuan earthquake survivors," Comprehensive Psychiatry, vol. 53, no. 5, pp. 616-622, 2012.

[56] F. Mammadova, M. Sultanov, A. Hajiyeva, M. Aichberger, and A. Heinz, "Translation and adaptation of the Zung Self-Rating Depression Scale for application in the bilingual Azerbaijani population," European Psychiatry, vol. 27, no. 2, pp. S27-S31, 2012.

[57] M. Trento, M. Raballo, M. Trevisan et al., "A cross-sectional survey of depression, anxiety, and cognitive function in patients with type 2 diabetes," Acta Diabetologica, vol. 49, no. 3, pp. 199203, 2012.

[58] O. Adogwa, S. L. Parker, D. N. Shau et al., "Preoperative Zung Depression Scale predicts outcome after revision lumbar surgery for adjacent segment disease, recurrent stenosis, and pseudarthrosis," The Spine Journal, vol. 12, no. 3, pp. 179-185, 2012.

[59] Y.-Q. Gao, B.-C. Pan, W. Sun, H. Wu, J.-N. Wang, and L. Wang, "Anxiety symptoms among Chinese nurses and the associated factors: a cross sectional study," BMC Psychiatry, vol. 12, article no. 141, 2012.

[60] M. Sawa, H. Yamashita, K. Fujimaki, G. Okada, T. Takahashi, and S. Yamawaki, "Depressive symptoms and apathy are associated with psychomotor slowness and frontal activation," European Archives of Psychiatry and Clinical Neurosciences, vol. 262, no. 6, pp. 493-499, 2012.

[61] W. C. Chang and J. B. K. Koh, "A measure of depression in a modern asian community: Singapore," Depression Research and Treatment, vol. 2012, Article ID 691945, 2012.

[62] L. Sapranaviciute, A. Perminas, and N. Pauziene, "Stress coping and psychological adaptation in the international students," Central European Journal of Medicine, vol. 7, no. 3, pp. 335-343, 2012.

[63] T. De Pasquale, E. Nucera, R. Boccascino et al., "Allergy and psychologic evaluations of patients with multiple drug intolerance syndrome," Internal and Emergency Medicine, vol. 7, no. 1, pp. 41-47, 2012.

[64] L.-L. Shen, L.-M. Lao, S.-F. Jiang et al., "A survey of anxiety and depression symptoms among primary-care physicians in China.," International Journal of Psychiatry in Medicine, vol. 44, no. 3, pp. 257-270, 2012.

[65] M.-L. Liu, F.-R. Liang, F. Zeng, Y. Tang, L. Lan, and W.-Z. Song, "Cortical-limbic regions modulate depression and anxiety factors in functional dyspepsia: A PET-CT study," Annals of Nuclear Medicine, vol. 26, no. 1, pp. 35-40, 2012. 
[66] Z. Huang, J. Hao, P. Su et al., "The impact of prior abortion on anxiety and depression symptoms during a subsequent pregnancy: Data from a population-based cohort study in China," Klinik Psikofarmakoloji Bülteni, vol. 22, no. 1, pp. 51-58, 2012.

[67] J. Li, Y. Shao, M. Yun, Z. Yan, K. Yu, and M. Li, "The mental health status of Chinese medical peacekeepers in Lebanon," Social Behavior and Personality, vol. 40, no. 3, pp. 375-380, 2012.

[68] Y.-R. Tang, W.-W. Yang, Y.-L. Wang, and L. Lin, "Sex differences in the symptoms and psychological factors that influence quality of life in patients with irritable bowel syndrome," European Journal of Gastroenterology \& Hepatology, vol. 24, no. 6, pp. 702707, 2012.

[69] M. Campbell et al., "A comparison of the psychometric strengths of the public-domain Zung Self-rating Depression Scale with the proprietary Beck Depression Inventory-II in Barbados," West Indian Medical Journal, vol. 61, no. 5, pp. 483488, 2012.

[70] O. Adogwa, S. L. Parker, D. N. Shau et al., "Preoperative Zung depression scale predicts patient satisfaction independent of the extent of improvement after revision lumbar surgery," The Spine Journal, vol. 13, no. 5, pp. 501-506, 2013.

[71] J. Balázs, M. Miklõsi, Á. Keresztény et al., “Adolescent subthreshold-depression and anxiety: Psychopathology, functional impairment and increased suicide risk," Journal of Child Psychology and Psychiatry and Allied Disciplines, vol. 54, no. 6, pp. 670-677, 2013.

[72] R. Li, J. Yang, J. Yang et al., "Depression in older patients with advanced colorectal cancer is closely connected with immunosuppressive acidic protein," Metabolic Brain Disease, vol. 29, no. 1, pp. 87-92, 2014.

[73] A. E. Lowery, T. Starr, L. K. Dhingra et al., "Frequency, characteristics, and correlates of pain in a pilot study of colorectal cancer survivors 1-10 years post-treatment," Pain Medicine, vol. 14, no. 11, pp. 1673-1680, 2013.

[74] X. Zhang, J. Gao, and J. Liu, "Prevalence rate and risk factors of depression in outpatients with premature ejaculation," BioMed Research International, vol. 2013, no. 1, Article ID 317468, 2013.

[75] Z. Guo, H. Tang, H. Li et al., "The benefits of psychosocial interventions for cancer patients undergoing radiotherapy," Health and Quality of Life Outcomes, vol. 11, no. 1, article 121, 2013.

[76] S. Nardelli, I. Pentassuglio, C. Pasquale et al., "Depression, anxiety and alexithymia symptoms are major determinants of health related quality of life (HRQoL) in cirrhotic patients," Metabolic Brain Disease, vol. 28, no. 2, pp. 239-243, 2013.

[77] A. Siennicki-Lantz, L. André-Petersson, P. Wollmer, and S. Elmståhl, "Depressive symptoms, atherosclerotic burden and cerebral blood flow disturbances in a cohort of octogenarian men from a general population," BMC Psychiatry, vol. 13, article no. $347,2013$.

[78] L. Liu, R. Pang, W. Sun et al., "Functional social support, psychological capital, and depressive and anxiety symptoms among people living with HIV/AIDS employed full-time," $B M C$ Psychiatry, vol. 13, article no. 324, 2013.

[79] D. Deb, "Depression and anxiety in heart failure patients in a South Indian population: A pilot study," Asian Journal of Biomedical and Pharmaceutical Sciences, vol. 3, no. 17, 2013.

[80] Y. Wang, X. Zhao, A. O’Neil, A. Turner, X. Liu, and M. Berk, "Altered cardiac autonomic nervous function in depression," BMC Psychiatry, vol. 13, article 187, 2013.
[81] F. Khorvash et al., "Investigating the anxiety level in Iranian medical residents in 2010-2011," International Journal of Preventive Medicine, vol. 4, 2, p. S318, 2013.

[82] S. Quintão, A. R. Delgado, and G. Prieto, "Validity study of the beck anxiety inventory (Portuguese version) by the rasch rating scale model," Psicologia: Reflexao e Critica, vol. 26, no. 2, pp. 305-310, 2013.

[83] A. Delibegovic and O. Sinanovic, "The influence of palliative care on the level of anxiety and depression in lung cancer patients.", Medical Archives, vol. 67, no. 4, pp. 263-265, 2013.

[84] Z. Klemenc-Ketiš and B. Peterlin, "Correlates of depression in the Slovenian working population," Archives of Industrial Hygiene and Toxicology, vol. 64, no. 4, pp. 489-495, 2013.

[85] V. Carli, C. Wasserman, D. Wasserman et al., "The Saving and Empowering Young Lives in Europe (SEYLE) Randomized Controlled Trial (RCT): Methodological issues and participant characteristics," BMC Public Health, vol. 13, no. 1, article no. 479, 2013.

[86] G. Grandi, A. Xholli, S. Ferrari, M. Cannoletta, A. Volpe, and A. Cagnacci, "Intermenstrual pelvic pain, quality of life and mood," Gynecologic and Obstetric Investigation, vol. 75, no. 2, pp. 97-100, 2013.

[87] J. Luo, G. Zhu, Q. Zhao et al., "Prevalence and risk factors of poor sleep quality among chinese elderly in an urban community: Results from the Shanghai aging study," PLoS ONE, vol. 8, no. 11, Article ID e81261, 2013.

[88] A. Akinsulore, O. O. Aloba, B. M. Mapayi, I. O. Oloniniyi, F. O. Fatoye, and R. O. A. Makanjuola, "Relationship between depressive symptoms and quality of life in Nigerian patients with schizophrenia," Social Psychiatry and Psychiatric Epidemiology, vol. 49, no. 8, pp. 1191-1198, 2014.

[89] S. Banth and A. Sharma, "A study of birth order and family size differences on depression," Indian Journal of Behaviour, vol. 5, no. 7, p. 114, 2014.

[90] A. R. Bhatti et al., "Anxiety and depression in patients suffering from chronic low backache," Methodology, 2013.

[91] M. Kaess et al., "Pathological internet use among european adolescents: psychopathology and self-destructive behaviours," European Child \& Adolescent Psychiatry, vol. 23, no. 11, pp. 10931102, 2014.

[92] M. Atteritano, S. Mazzaferro, A. Bitto et al., "Genistein effects on quality of life and depression symptoms in osteopenic postmenopausal women: a 2-year randomized, double-blind, controlled study," Osteoporosis International, vol. 25, no. 3, pp. 1123-1129, 2014.

[93] I.-T. Lee, C.-P. Fu, W.-J. Lee et al., "Brain-derived neurotrophic factor, but not body weight, correlated with a reduction in depression scale scores in men with metabolic syndrome: A prospective weight-reduction study," Diabetology \& Metabolic Syndrome, vol. 6, no. 1, article no. 18, 2014.

[94] I. I. Vlachos, C. Barbatis, M. Tsopanomichalou, and L. AbouAssabeh, "Correlation between depression, anxiety, and polymorphonuclear cells' resilience in ulcerative colitis: The mediating role of heat shock protein 70," BMC Gastroenterology, vol. 14, p. 77, 2014.

[95] Y. Ding, J. Qu, X. Yu, and S. Wang, "The mediating effects of burnout on the relationship between anxiety symptoms and occupational stress among community healthcare workers in China: A cross-sectional study," PLoS ONE, vol. 9, no. 9, Article ID e107130, 2014.

[96] M. Trento, M. Trevisan, M. Raballo et al., "Depression, anxiety, cognitive impairment and their association with clinical and 
demographic variables in people with type 2 diabetes: A 4-year prospective study," Journal of Endocrinological Investigation, vol. 37, no. 1, pp. 79-85, 2014.

[97] M. Fernández-Matarrubia, M. L. Cuadrado, C. M. SánchezBarros et al., "Prevalence of migraine in patients with restless legs syndrome: A case-control study," Headache: The Journal of Head and Face Pain, vol. 54, no. 8, pp. 1337-1346, 2014.

[98] Q. Feng, Q.-L. Zhang, Y. Du, Y.-L. Ye, and Q.-Q. He, "Associations of physical activity, screen time with depression, anxiety and sleep quality among Chinese college freshmen," PLoS ONE, vol. 9, no. 6, Article ID e100914, 2014.

[99] Y. Hou, X. Li, L. Yang et al., "Factors associated with depression and anxiety in patients with end-stage renal disease receiving maintenance hemodialysis," International Urology and Nephrology, vol. 46, no. 8, pp. 1645-1649, 2014.

[100] F. Khorvash et al., "The relationship between residents interest to their specialty field and their level of anxiety," Journal of Education and Health Promotion, vol. 3, 2014.

[101] S. Liu, R. Wu, L. Li et al., "The prevalence of anxiety and depression in Chinese asthma patients," PLoS ONE, vol. 9, no. 7, Article ID e103014, 2014.

[102] A. La Fianza, C. Dellafiore, D. Travaini et al., "Effectiveness of a single education and counseling intervention in reducing anxiety in women undergoing hysterosalpingography: A randomized controlled trial," The Scientific World Journal, vol. 2014, Article ID 598293, 2014.

[103] J. Bobić, S. Cvijetić, and J. Macan, "Personality and selfperception of physical and emotional health among first-year university students," Drustvena Istrazivanja, vol. 24, no. 2, pp. 219-237, 2015.

[104] S.-B. Chen, H. Hu, Y.-S. Gao, H.-Y. He, D.-X. Jin, and C.Q. Zhang, "Prevalence of clinical anxiety, clinical depression and associated risk factors in Chinese young and middle-aged patients with osteonecrosis of the femoral head," PLOS ONE, vol. 10, no. 3, Article ID e0120234, 2015.

[105] Y. Jiang, M. Yang, H. Wu et al., "The relationship between disease activity measured by the BASDAI and psychological status, stressful life events, and sleep quality in ankylosing spondylitis," Clinical Rheumatology, vol. 34, no. 3, pp. 503-510, 2015.

[106] M. Rus Makovec, N. Vintar, and S. Makovec, "Self-Reported Depression, Anxiety and Evaluation of Own Pain in Clinical Sample of Patients with Different Location of Chronic Pain/ Samoocenjena Depresivnost in Anksioznost Ter Evalvacija Lastne Bolečine V Kliničnem Vzorcu Pacientov Z Različno Lokacijo Kronične Bolečine," Slovenian Journal of Public Health, vol. 54, no. 1, pp. 1-10, 2015.

[107] P. Kourkoveli, S. Rammos, J. Parissis, A. Maillis, D. Kremastinos, and I. Paraskevaidis, "Depressive Symptoms in Patients with Congenital Heart Disease: Incidence and Prognostic Value of Self-Rating Depression Scales," Congenital Heart Disease, vol. 10, no. 3, pp. 240-247, 2015.

[108] M. Shi, L. Liu, Z. Y. Wang, and L. Wang, “The mediating role of resilience in the relationship between big five personality and anxiety among chinese medical students: A cross-sectional study," PLoS ONE, vol. 10, no. 3, Article ID e0119916, 2015.

[109] A. Stefanidou, D. Bouros, M. Livaditis, A. Pataka, and P. Argyropoulou-Pataka, "Psychological Characteristics and Smoking Cessation Outcomes in a Sample of Greek Smokers," Current Psychology, vol. 34, no. 1, pp. 66-81, 2015.

[110] G. Pozzi, A. Frustaci, D. Tedeschi et al., "Coping strategies in a sample of anxiety patients: Factorial analysis and associations with psychopathology," Brain and Behavior, vol. 5, no. 8, Article ID e00351, 2015.

[111] L. Yuan, Y. Tian, F. Zhang et al., "Decision-making in patients with hyperthyroidism: A neuropsychological study," PLOS ONE, vol. 10, no. 6, Article ID e0129773, 2015.

[112] W. Yin, L. Pang, X. Cao et al., "Factors associated with depression and anxiety among patients attending communitybased methadone maintenance treatment in China," Addiction, vol. 110, no. 1, pp. 51-60, 2015.

[113] S. Li, M. Qi, W. Yuan, and H. Chen, "The Impact of the Depression and Anxiety on Prognosis of Cervical Total Disc Replacement," The Spine Journal, vol. 40, no. 5, pp. E266-E271, 2015.

[114] K. Hirao, "Difference in mental state between Internet-addicted and non-addicted Japanese undergraduates," International Journal of Adolescent Medicine and Health, vol. 27, no. 3, pp. 307-310, 2015.

[115] Z. Lou, Y. Li, Y. Yang, L. Wang, and J. Yang, "Affects of anxiety and depression on health-related quality of life among patients with benign breast lumps diagnosed via ultrasonography in China," International Journal of Environmental Research and Public Health, vol. 12, no. 9, pp. 10587-10601, 2015.

[116] X. Yang, L. Wang, C. Hao et al., "Sex partnership and selfefficacy influence depression in Chinese transgender women: A cross-sectional study," PLoS ONE, vol. 10, no. 9, Article ID e0136975, 2015.

[117] M. Trento, L. Charrier, M. Salassa et al., "Depression, anxiety and cognitive function in patients with type 2 diabetes: an 8year prospective observational study," Acta Diabetologica, vol. 52, no. 6, pp. 1157-1166, 2015.

[118] M. M. A. Babakhanian, Z. A. M. A. Mehrjerdi, and Y. M. D. Shenaiy, "Sexual dysfunction in male crystalline heroin dependents before and after MMT: A pilot study," Archives of Iranian Medicine, vol. 15, no. 12, pp. 751-755, 2012.

[119] J. W. L. Ng, R. Kwan, and C. C. S. Cheok, "Clinical and Functional Outcomes in Young Adult Males With ADHD," Journal of Attention Disorders, vol. 21, no. 6, pp. 465-474, 2017.

[120] J. Fischer and K. Corcoran, Measures for Clinical Practice And Research, Oxford University Press, New York, NY, USA, 2007.

[121] N. S. Schutte and J. M. Malouff, Sourcebook of Adult Assessment Strategies, Plenum Press, New York, NY, USA, 1995. 


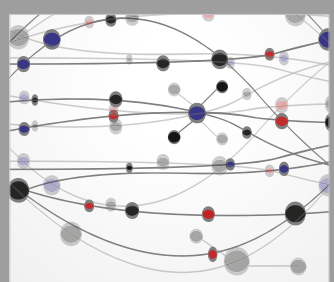

The Scientific World Journal
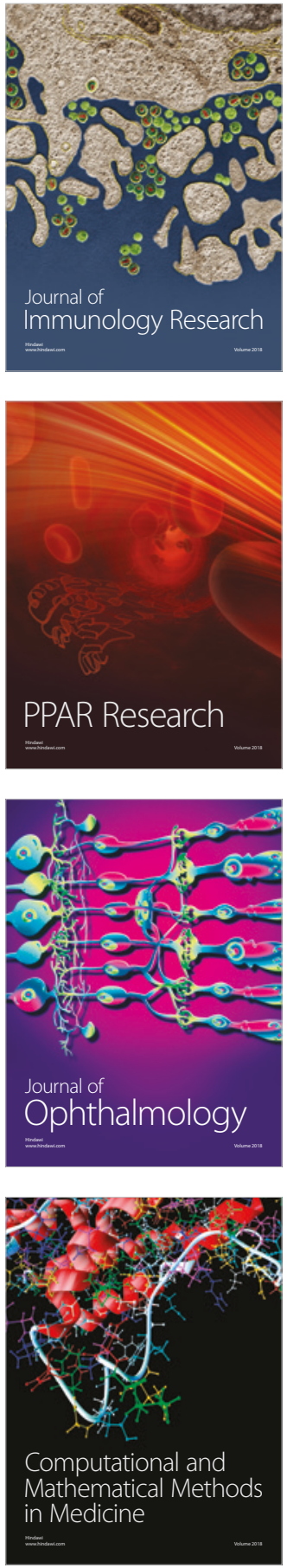

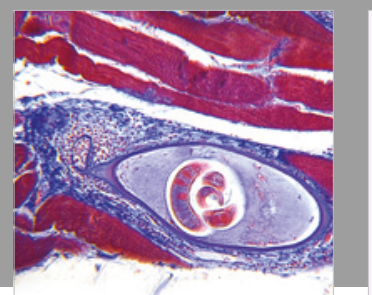

Gastroenterology Research and Practice

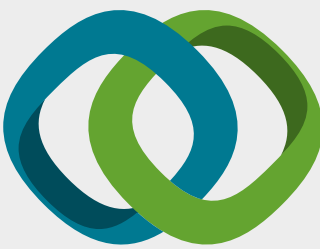

\section{Hindawi}

Submit your manuscripts at

www.hindawi.com
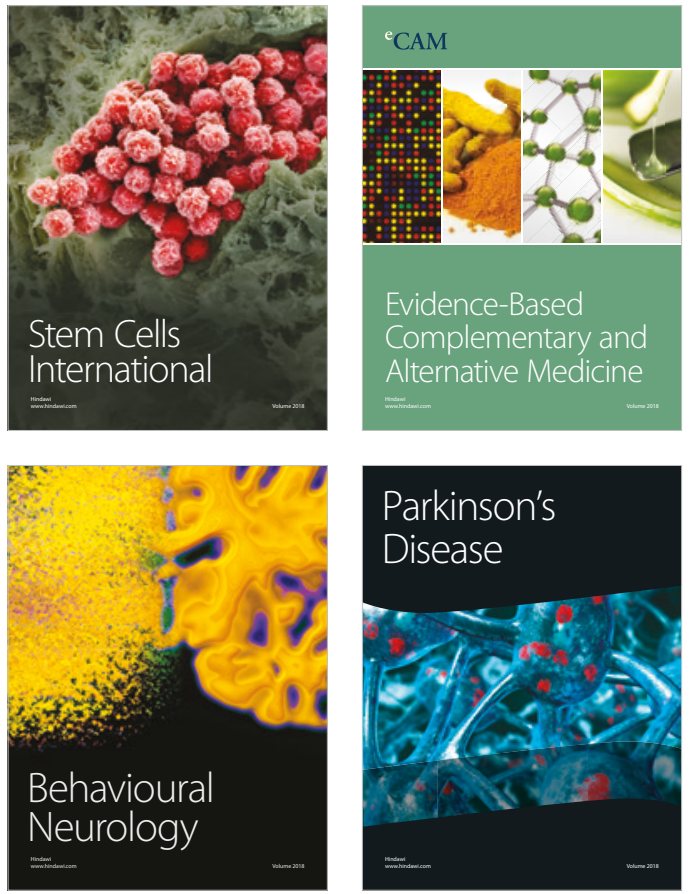

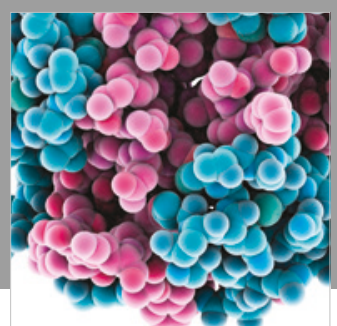

ournal of

Diabetes Research

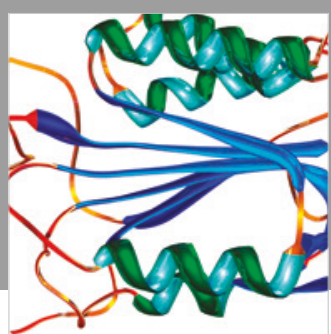

Disease Markers
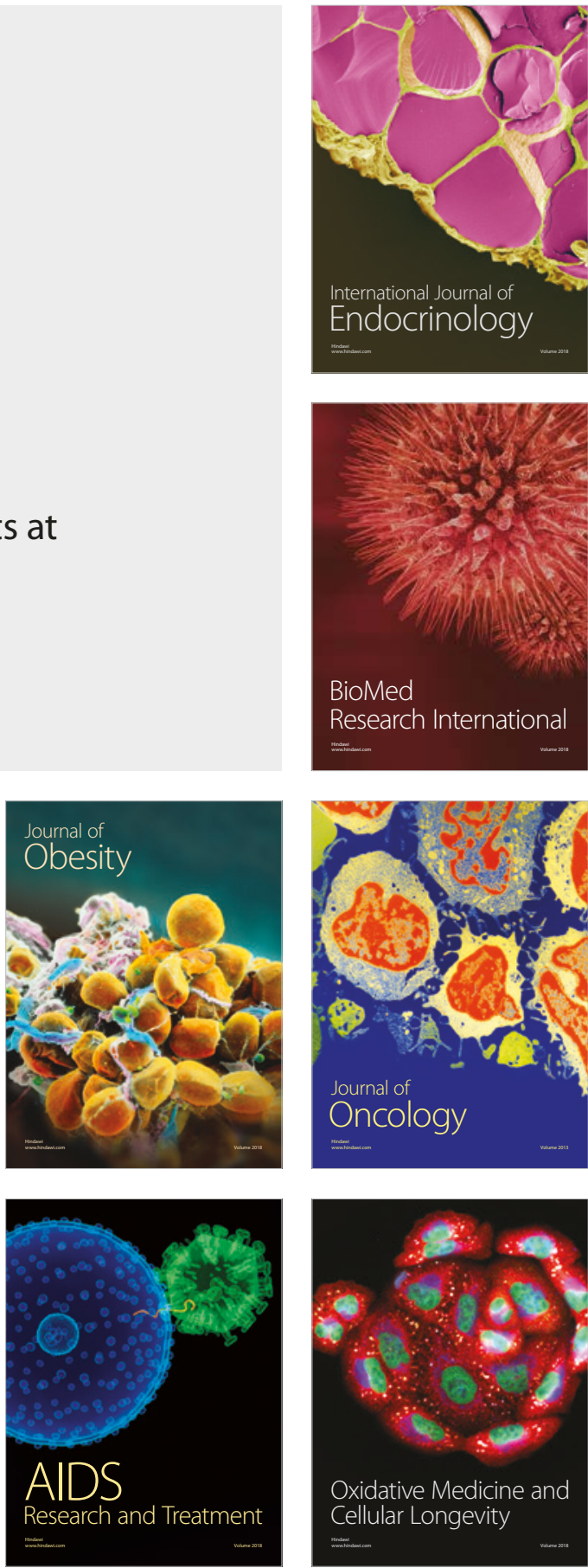